\title{
Pluripotent stem cells for Parkinson's disease: progress and challenges
}

Xianmin Zeng ${ }^{1}$ and Larry A Couture*2

\begin{abstract}
Parkinson's disease (PD) is a common debilitating neurodegenerative disease. The motor symptoms of PD are caused mainly by a progressive loss of dopaminergic neurons from the substania nigra, resulting in a loss of dopamine production. Current therapies are palliative and, in the long term, ineffective. In addition, some can result in significant clinical side effects. The relatively localized pathology of PD makes it an ideal candidate for cell replacement therapy. Initial efforts focused on fetal cell transplantation, and significant clinical benefit lasting more than 10 years has been reported in some cases. However, the approach is controversial and results have been inconsistent. Inherent limitations of this approach for widespread use are the limited availability and variability of transplant material. In contrast, the self-renewal and differentiation potential of human pluripotent stem cells (hPSCs) make them a promising alternative cell source for cell replacement therapy for PD. Efforts in the past decade have demonstrated that hPSCs can be induced to differentiate in culture to functional dopaminergic neurons. Studies in delivering these cells into PD animal models have demonstrated survival, engraftment, and behavioral deficit improvements. Several groups are developing these cells with clinical trials in mind. Here, we review the state of the technology and consider the suitability of current manufacturing processes, cell purity, and tumorgenicity for clinical testing.
\end{abstract}

\section{Parkinson's disease}

Parkinson's disease (PD) is the second most common chronic neurodegenerative disease and is characterized

*Correspondence: Icouture@coh.org

2Beckman Research Institute of City of Hope, 1500 East Duarte Road, Duarte, CA 91711, USA

Full list of author information is available at the end of the article by hyperkinesia, tremors, and muscle rigidity [1]. The major underlying pathology is characterized by progressive degeneration of mesencephalic dopaminergic (DA) neurons of the substantia nigra pars compacta, resulting in a reduction in the level of dopamine production in the dorsal striatum [1]. Clinical symptoms typically appear when $60 \%$ to $80 \%$ of the estimated half a million DA neurons in the substantia nigra are lost [1]. Conventional palliative treatments for PD attempt to replace lost dopamine activity or increase the activity of the remaining dopamine and include levodopa and carbidopa combinations, dopamine receptor agonists, muscarinic anticholinergics, and monoamine oxidase or catechol-omethyl transferase inhibitors. Surgical procedures, including pallidotomy and deep brain stimulation, are also available but are suitable for only a small portion of the patient population and their long-term benefit is unclear. Although pharmaceutical treatments are effective early in the disease and surgical procedures can provide substantial symptomatic relief in advanced stages of PD, these symptomatic treatment modalities do not repair or replace neurons and their effectiveness has been observed to decline over time, and some patients become desensitized to treatment [2] and some develop drugrelated diskenesias [3].

\section{Cell therapy for Parkinson's disease}

The lack of an effective long-term curative pharmaceutical or surgical therapy for PD has led to efforts over the past three decades to develop a cell replacement approach. Although lower brain stem and cortical areas may also be affected in PD, the largely localized loss of the relatively small population of DA neurons of the substantia nigra makes targeted delivery of dopamineproducing replacement cells appealing. After a decade of differentiation methodology development and animal studies, human pluripotent stem cell (hPSC)-derived DA neurons have emerged as a promising approach and appear headed for clinical trials.

Evidence supporting the rationale for developing an hPSC-derived DA cell replacement therapy is provided by animal studies that since the early 1980s have evaluated the effects of transplantation of fetal mesencephalic 
tissue containing nigral DA cells into the striatum of rodents and non-human primates [4-9]. The majority of these experimental studies demonstrated that this approach is capable of reversing behavioral parkinsonism despite minimal survival and integration of engrafted cells in the host brain, providing the basis for subsequent clinical trials in which fetal mesencephalic tissue was transplanted in patients with PD [10-13]. Although evidence of significant clinical benefit has been reported $[10,11]$, reports concerning the efficacy of this type of treatment [14] and the occurrence of dyskinesias (reviewed in Isacson and Kordower [15] in 2008), which might be due to contaminating serotonergic neurons in the cell graft (as reported by Politis and colleagues [16] in 2010) have varied, underscoring the need to obtain cells through a controllable manufacturing processes that minimizes or eliminates undesirable contaminating cell types.

Although surviving DA neurons have been observed after more than 14 years following fetal cell transplants, Lewy bodies, a hallmark of PD, have been observed in some of the transplanted cells in a subpopulation of patients, raising the concern that transplanted/donor cells might undergo progressive neurodegeneration. Whether this is a reaction to the surrounding pathological tissue or the transmission of an adventitious agent from the host remains unclear (reviewed by Braak and Del Tredici [17] in 2008).

This variation likely results from differences in cell preparation, cell dose, and specific delivery site. In spite of this, evidence of significant clinical benefit has been reported [10,11]. Results of these trials, however, have raised a number of concerns from ethical, practical, and clinical standpoints. Furthermore, tissue availability (multiple fetuses are needed for each transplantation procedure) is not compatible with large-scale application of fetal cell transplants. Finally, the clinical benefits of fetal cell transplantation in patients with PD have been inconsistent [12], emphasizing this procedure's potential pitfalls that may derive from the variable cell composition (DA neurons represent only a small proportion of mesencephalic tissue), donor age, and methods of preparation of the transplants [10-12].

Ex vivo expansion of a neuronal population from adult or fetal neural stem cells (NSCs) might address some of the limitations of the fetal transplant approach but has not been reported and, owing to the limited capacity of these cells to proliferate, may not be possible. Despite the limitations of this approach, the important conclusion after three decades of animal and human studies is that a cell replacement approach to PD can provide significant long-term clinical benefit. The demonstrated proof-of-concept, along with the limitations of this approach, has driven the effort to identify an alternative cell source.

\section{Pluripotent stem cells as a cell replacement therapy}

Human embryonic stem cells (hESCs) and adult stem cell sources such as mesenchymal stem cells have been shown to be capable of generating DA neurons in cell culture models. Whereas both adult and embryonic PSC sources have shown promise, hESC sources have made the most progress.

It has been less than 15 years since the first report of the successful isolation and culture of hESCs [18]. Although undifferentiated pluripotent hESCs and human induced pluripotent stem cells (hiPSCs) are not likely to be used directly as clinical products, they do provide a starting cell source for many differentiated cell types. The unlimited potential for self-renewal of these hPSCs and their capacity to be directed to differentiate by manipulation of their cell culture environment make them promising alternatives to adult or fetal tissue in many regenerative, medical applications. The ability to reproducibly generate large batches of differentiated cells allows for the standardization, consistency, and detailed characterization that will facilitate animal studies and that will be required prior to testing in human studies.

The clear clinical potential of these cells has led to significant efforts to optimize methods to direct their differentiation into a variety of specific precursor or terminally differentiated cell types that could have considerable benefit in the treatment of a broad range of human disease and genetic disorders, including PD. A critical advancement toward the therapeutic use of hPSCs in PD has been the demonstration that authentic DA neurons can be generated from hPSCs $[19,20]$ and that grafts can release dopamine and ameliorate behavioral deficits in rodent PD models [21-27]. Although these studies are encouraging, development of these cells for clinical study requires the establishment of a scalable process that produces a sufficient yield and purity of DA neurons that will be compatible with US Food and Drug Administration requirements for safe and well-characterized cell products.

\section{Methods of generating dopaminergic neurons}

During the past decade, there has been an explosion in developing methods to direct DA neuronal differentiation of hESCs, and many groups have reported the generation of tyrosine hydroxylase (TH)-positive DA neurons from hESCs [21,22,27-32]. Most of these methods were initially developed by using mouse ESCs (mESCs) and subsequently adapted for use with hESCs. The approaches used to generate DA neurons from ESCs have used information from developmental biology. In general, ESCs are systematically exposed to factors that induce differentiation in a stepwise fashion, thereby directing the cells toward specific cell fates. While these methods vary 
in the process of neuronal differentiation, efficiency of DA neuron generation, and the degree of DA neuron characterization, they define two fundamental approaches: (a) via NSCs by embryoid body (EB) formation followed by exposure to various growth factors and (b) by coculture with stromal cells or astrocytes. Both approaches were first developed in $\mathrm{mESC}$ systems and later were adapted with modifications to hESCs. Variations of both protocols include direct differentiation of hESCs into a neural lineage without going through the EB stage, using conditioned media from mouse stromal cells, and a defined media cocktail based in part on factors secreted by stromal cells and work done in transgenic mouse models [33].

The classic method for generating DA neurons from mESC lines is by EB formation followed by selection for neural precursors followed by expansion and then induction of neuronal differentiation by a combination of several growth factors [34]. The procedure generates a small number of DA neurons (about 7\% of Tul1-positive neurons, which comprises about $72 \%$ of the total surviving cell number; that is, about $5 \%$ of the final cell population were $\mathrm{TH}$-positive neurons), but the percentage of TH-positive cells increases to $33 \%$ of the total number of neurons, or about $20 \%$ of total cells, when Shh, FGF8, and ascorbic acid are added. DA neuron cell yields can be further enhanced by using genetically modified $\mathrm{mESCs}$ by overexpression of transcription factor nuclear receptor related 1 (Nurr1) [9].

Initial efforts to adapt mESC differentiation procedures to hESC cultures demonstrated that human neural precursors and neurons could be similarly generated via $\mathrm{EB}$ formation $[35,36]$ in the early 2000s. This method, however, did not produce mesencephalic post-mitotic neurons, such as midbrain DA neurons, at a high frequency. More efficient generation of DA neurons through EB formation was reported a few years later [31,32]. Schulz and colleagues [31] reported the successful differentiation of hESCs to form neurons expressing markers of the midbrain DA lineage in a serum-free suspension culture system in the absence of added neuron-inducing agents or growth factors. Large networks of TH-positive neurons were generated in the aggregates (in suspension) that co-expressed a panel of markers of the midbrain DA lineage. In another study, DA subtype-specific neurons were efficiently generated by applying Shh and FGF8 in a specific sequence [32]. The authors suggested that early exposure of FGF8 to neural precursors prior to the expression of Sox1 was required for efficient generation of midbrain DA neurons but that treatment with FGF8 and Shh in Sox1-expressing neural precursors resulted in the efficient production of forebrain DA neurons. Both groups reported that $\mathrm{hESC}$-derived DA neurons were electrophysiologically active and could release dopamine upon depolarization with $\mathrm{KCl}$. Although these results showed that it was technically feasible to generate authentic, electrically mature neurons that had the biochemical and functional phenotype of a striatal DA neuron, the overall efficiency of DA differentiation with these methods was relatively low, resulting in high levels of contaminating cells. In addition, these methods employed a process of differentiation from hESCs to DA neurons which in general takes 8 weeks, resulting in a low yield of DA neurons from the starting hESC culture. Significant improvements in DA cell yields from differentiation via EB formation have recently been made. One of these improvements took advantage of being able to generate and store cells at an intermediate stage of the differentiation process, the NSC stage (with nearly $100 \%$ purity) [26]. The homogeneous NSCs can then be differentiated into DA neurons, resulting in greater than $40 \%$ of the final cell product expressing TH after only 3 to 4 weeks of differentiation [26].

DA neurons can be generated efficiently from hESCs by co-culture methods. Generation of DA neurons by coculturing with stromal cells (for example, PA6 and MS5) was first reported by Kawasaki and colleagues [37] with mESCs. The method is efficient and rapid, as evidenced by the observations that more than $90 \%$ of cells became neural cell adhesion molecule-positive $\left(\mathrm{NCAM}^{+}\right)$when cultured on the mouse stromal cell lines, PA6 or MS5, for a week and that about $30 \%$ of the TuJ1-positive neurons (about $52 \%$ of total cells) were TH-positive after 12 days of co-culture. The same group later successfully used the co-culture method to produce DA neurons from nonhuman primate ESCs [38]. The yield of DA neurons by this simple co-culture method is comparable to the more complex method of overexpression of Nurr1 combined with multiple growth factors via EB formation described in the previous section.

Several laboratories reported the adaptation of the mESC stromal cell co-culture method of generation of DA neurons to hESCs in 2004. Perrier and colleagues [21] reported that hESCs differentiated into midbrain DA neurons after co-culture with the mouse stromal cell line MS5 for 4 weeks followed by 2 to 3 weeks of culture in the presence of Shh and FGF8 without stromal feeder cells. The neurons produced by this procedure had midbrain DA characteristics at a high efficiency, and 79\% of the neurons were TH-positive. DA neurons could also be generated from hESCs by co-culturing hESCs with mouse PA6 stromal cells in the presence of glial cell linederived neurotrophic factor (GDNF) [30]. Zeng and colleagues [22] described the efficient generation of DA neurons by co-culture with PA6 cells without the addition of growth factors. After 3 weeks of co-culture, about $80 \%$ of the colonies contained TH-positive cells that coexpressed many midbrain and DA markers. In addition, 
DA neurons generated by co-culture with stromal cells produced a significant amount of dopamine in response to $\mathrm{KCl}$ stimulation and displayed neuronal electrophysiological properties. These methods were further optimized by a combination of growth factors and by use of media conditioned on stromal cells at various stages of neural differentiation [33,39]. Co-culture with other cell types such as astrocytes was also reported to be efficient in generating functional DA neurons from hESCs [27].

Although the molecular mechanism underlying DA differentiation by stromal cells is not clear, factors secreted by PA6 cells seem to be sufficient for DA neuronal induction and maturation after neural initiation $[33,39]$. Overall, the stromal cell co-culture method has both advantages and disadvantages in the production of DA neurons as compared with differentiation via EB methods. The co-culture method is technically simpler, and neural differentiation of hESCs is not only efficient but rapid. However, the development of hPSC-derived DA neurons as clinical therapies requires efficient manufacturing methods that will be compatible with good manufacturing practices (GMPs). Co-culture with mouse stromal cells raises regulatory concerns and makes the method less feasible compared with the EB method, which requires only growth factors. Importantly, Swistowski and colleagues [26] have demonstrated the efficient generation of functional DA neurons from hiPSCs by using an improved EB method under fully xeno-free culture conditions. Transplants into a rat PD model with cells grown under these 'GMP-compatible' conditions resulted in behavioral improvements comparable to those reported for cells produced by using non-xeno-free culture conditions.

\section{Dopaminergic neuron cell product purity}

Although considerable progress has been made in developing differentiation protocols capable of yielding a high percentage of midbrain DA neurons, the cell populations generated from these protocols remain heterogeneous and may contain various percentages of non-DA neurons (for example, motoneurons and GABAergic neurons), neural progenitor cells, non-neuronal cells (for example, astrocytes and oligodendrocytes), and non-neural cells (for example, undifferentiated cells). While $\mathrm{TH}$ is the most common marker of DA neurons, recent reports suggested that additional determinants such as Lmx1a and FoxA2 are important for the quality of midbrain DA neurons. A combination of these markers together with more mature or specific DA markers, including DAT, Girk2, and VMAT, may be useful to assess the overall quality of DA neuron preparation, as reported in 2010 by Fasano and colleagues [40] and Cooper and colleagues [41].

While the value or risks of non-DA neuronal cell 'contaminants' in grafts are unknown, the presence of undifferentiated hPSCs or NSCs in a cell product has been reported to result in proliferative cell growths or teratoma formation [27,42-45], suggesting that purification of differentiated cell products may be required for clinical use. In one study, purification of the cell product by cytometric sorting to remove SSEA-1 pluripotent cells was effective in reducing the teratoma formation observed with non-purified DA cells in a rat model while maintaining behavioral recovery by purification of the cell product by cytometric sorting to remove SSEA-1 pluripotent cells [43]. Along with another study [27], this study not only demonstrates the potential of hPSCderived cell products to retain cells with tumorigenic potential even after a prolonged differentiation process but also points to the value of a post-differentiation purification strategy. However, the tumorigenic potential of sorted cell populations may be difficult to judge in PD animal models in which low cell doses are used. Additional efforts will be required to demonstrate the tumorigenic potential of cells made by using the optimized differentiation process and cell doses that will be required for human trials.

Concerns have also been raised over whether current differentiation protocols provide efficient patterning of DA neurons to the A9 type seen in the substantia nigra. hESC- and iPSC-derived TH-positive DA neurons transplanted into the striatum of 6-hydroxydopamine (6-OHDA)-lesioned rats survived for several months and resulted in reproducible and some behavior recovery in one study [19], but whereas $50 \%$ of the transplanted THpositive DA neurons co-expressed Girk2, as is typically seen in DA neurons of the substantia nigra, only a few DA neuron axons were seen to innervate the host striatum. Although Girk2 and TH are typically coexpressed on DA neurons of the substantia nigra, this pattern is also seen in a subset of other neurons outside the A9 region [46], suggesting that characterization of hESC-derived DA neuron populations with these markers alone, or by $\mathrm{TH}$ alone, is inadequate to confirm the proper substantia nigra A9 phenotype. When transplanted cells were further analyzed, the authors noted that expression of the transcription factor FoxA2, also typically seen together with $\mathrm{TH}$ in the midbrain, was absent. A combination of TH and Girk2 with wellcharacterized midbrain and DA markers such as DAT, AADC, VMAT, Nurr1, Pitx3, and Lmx1b [22], along with more novel markers such as FoxA2 [19], will be useful in the development of differentiation methods and to determine the optimal phenotype of neurons to be transplanted.

\section{Induced pluripotent stem cells}

In addition to having characteristics similar to hESCs and avoiding the ethical and regulatory dilemmas associated 
with hESCs, iPSCs offer the potential to provide patientspecific cell replacement therapies. Although the requirement for immunosuppression with hESC-derived cell replacement therapy for PD is not clear, patient-specific iPSC products may avoid the immunorejection problems commonly associated with allogeneic transplants. In addition, iPSC lines have been reported, in some cases, to retain an epigenetic 'memory' of their cells of origin [47] that may skew their differentiation potential toward specific fates [48], although the durability of this memory over extended culture periods is not clear. While iPSC memory may be a potential disadvantage for some research applications, a differentiation bias of an allogeneic iPSC line to a neural progenitor fate might provide higher yields or greater purity following differentiation. Improved differentiation efficiency would facilitate the scale of manufacture that will be required for clinical studies.

Although there may be immunological advantages to the use of autologous iPSC-derived DA neurons, there are also potential pitfalls. The time and cost required to produce an autologous iPSC-derived DA product may be prohibitive. In addition, cells derived from patients with familial forms of PD carrying PD mutations might need to be genetically corrected before transplantation back to the patients, and this requires additional regulations, safety testing, and costs. Extensive safety testing of autologous iPSC-derived cell products may not be practical and could result in increased risk of adverse events. As we learn more about the mechanism of the PD disease process, we will be able to determine whether this type of cell population is suitable for disease applications.

Efforts to pursue an iPSC alternative to hESCs for PD are under way. An initial report of motor recovery in a PD rat model after transplantation of differentiated cells from a mouse iPSC line [43] was followed by the report of the successful generation of iPSC lines derived from patients with PD [20]. Subsequently, several groups reported on the successful generation of midbrain DA neurons with hiPSC- and PD-derived iPSCs [19,41]. Recent reports describe hiPSC-derived DA neuron cell survival and engraftment as well as behavioral improvements in PD rat models [42,49,50]. These reports demonstrate that midbrain DA neurons can be successfully generated from iPSCs and that these cells can function properly.

Although there are several advantages of iPSCs, there are concerns about chromosomal aberrations and epigenetic modifications that have been reported to occur during reprogramming and that may be maintained through differentiation [47,51]. It is not clear what the effect of these mutations and aberrations will be on the activity or safety of differentiated cells or whether they will persist after extended culture of an iPSC line [52], but there is a clear need for a better understanding of these cells before they are used in clinical trials. In addition, the differentiation potential of iPSC lines may change over time in culture, requiring careful characterization of differentiated cell products to ensure consistency and reproducibility in animal studies [53]. It is clear that a better understanding of these cells will be essential before they are used in clinical trials.

\section{Conclusions}

A number of groups have made considerable progress in demonstrating that authentic A9 DA neurons can be produced in vitro with high efficiency from hESC and iPSC lines, including lines derived from patients with PD. Several of these groups have also shown survival and engraftment of these cells in the 6-OHDA rat model as well as evidence of dopamine release and correction of behavioral deficits. These studies, combined with the proof-of-concept provided by human trials using fetusderived DA neurons, provide compelling evidence to justify the development of these cells for use in human clinical trials. However, there are outstanding issues to be resolved. In many cases, the behavioral improvements observed in animal studies are modest, and there is currently limited evidence that complex motor deficits can be corrected with engrafted hPSC-derived DA neurons [27]. This may be due to the variable or low number of cells in the grafts, limitations of the rodent PD models, or differences in the microenvironmental signals between human and rat cells in the brain or a result of influences from contaminating non-A9 DA cells in the graft. Better animal model systems would facilitate the development of these cells, and predictive long-term efficacy studies with non-human primate models such as the MPTP monkey model will be of great value. In addition, other issues need to be addressed, including the low survival rate of DA neurons in grafts, difficulty in integrating transplanted cells into the host brain's circuitry, defining the number of DA neurons needed for a transplant (Freed and colleagues [14] suggested that at least about 20,000 cells are needed for transplantation), site of injection, and graft-induced dyskinesia. Some of these issues, such as cell number or dose, injection site, and cell survival, may not be resolved without information from human clinical studies, but it is certain that addressing these issues will require properly controlled animal and human studies using a wellcharacterized cell product made with defined protocols and reagents.

\section{Abbreviations}

6-OHDA, 6-hydroxydopamine; DA, dopaminergic; EB, embryoid body; ESC, embryonic stem cell; GMP, good manufacturing practice; hESC, human embryonic stem cell; hiPSC, human induced pluripotent stem cell; hPSC, human pluripotent stem cell; iPSC, induced pluripotent stem cell; mESC, 
mouse embryonic stem cell; NSC, neural stem cell; Nurr1, nuclear receptor related 1; PD, Parkinson's disease; PSC, pluripotent stem cell; TH, tyrosine hydroxylase.

\section{Competing interests}

The authors declare that they have no competing interests.

\section{Acknowledgments}

The authors would like to acknowledge the contributions of Melissa Carpenter for her critical review of the manuscript.

\section{Author details}

'Buck Institute for Age Research, 8001 Redwood Boulevard, Novato, CA 94945, USA. ${ }^{2}$ Beckman Research Institute of City of Hope, 1500 East Duarte Road, Duarte, CA 91711, USA.

\section{Published: 15 April 2013}

\section{References}

1. Graybiel AM, Hirsch EC, Agid Y: The nigrostriatal system in Parkinson's disease. Adv Neurol 1990, 53:17-29.

2. Lindvall O, Kokaia Z: Prospects of stem cell therapy for replacing dopamine neurons in Parkinson's disease. Trends Pharmacol Sci 2009, 30:260-267.

3. Politis M: Dyskinesias after neural transplantation in Parkinson's disease: what do we know and what is next? BMC Med 2010, 8:80.

4. Perlow MJ, Freed WJ, Hoffer BJ, Seiger A, Olson L, Wyatt RJ: Brain grafts reduce motor abnormalities produced by destruction of nigrostriatal dopamine system. Science 1979, 204:643-647.

5. Björklund A, Dunnett SB, Stenevi U, Lewis ME, Iversen SD: Reinnervation of the denervated striatum by substantia nigra transplants: functional consequences as revealed by pharmacological and sensorimotor testing. Brain Res 1980, 199:307-333.

6. Freed WJ, Perlow MJ, Karoum F, Seiger A, Olson L, Hoffer BJ, Wyatt RJ: Restoration of dopaminergic function by grafting of fetal rat substantia nigra to the caudate nucleus: long-term behavioral, biochemical, and histochemical studies. Ann Neurol 1980, 8:510-519.

7. Studer L, Tabar V, McKay RD: Transplantation of expanded mesencephalic precursors leads to recovery in parkinsonian rats. Nat Neurosci 1998, 1:290-295.

8. Bjorklund LM, Sánchez-Pernaute R, Chung S, Andersson T, Chen IY, McNaught KS, Brownell AL, Jenkins BG, Wahlestedt C, Kim KS, Isacson O: Embryonic stem cells develop into functional dopaminergic neurons after transplantation in a Parkinson rat model. Proc Natl Acad Sci U S A 2002, 99:2344-2349

9. Kim JH, Auerbach JM, Rodríguez-Gómez JA, Velasco I, Gavin D, Lumelsky N, Lee SH, Nguyen J, Sánchez-Pernaute R, Bankiewicz K, McKay R: Dopamine neurons derived from embryonic stem cells function in an animal model of Parkinson's disease. Nature 2002, 418:50-56

10. Freed CR, Breeze RE, Rosenberg NL, Schneck SA, Kriek E, Qi JX, Lone T, Zhang YB, Snyder JA, Wells TH, Ramig LO, Thompson L, Mazziotta JC, Huang SC, Grafton ST, Brooks D, Sawle G, Schroter G, Ansari AA: Survival of implanted fetal dopamine cells and neurologic improvement 12 to 46 months after transplantation for Parkinson's disease. N Engl J Med 1992, 327:1549-1555.

11. Lindvall O, Sawle G, Widner H, Rothwell JC, Bjorklund A, Brooks D, Brundin P, Frackowiak R, Marsden CD, Odin P, Rehncrona S: Evidence for long-term survival and function of dopaminergic grafts in progressive Parkinson's disease. Ann Neurol 1994, 35:172-180.

12. Kordower JH, Freeman TB, Snow BJ, Vingerhoets FJG, Mufson EJ, Sanberg PR, Hauser RA, Smith DA, Nauert GM, Perl DP, Olanow CW: Neuropathological evidence of graft survival and striatal reinnervation after the transplantation of fetal mesencephalic tissue in a patient with Parkinson's disease. N Engl J Med 1995, 332:1118-1124.

13. Ma Y, Tang C, Chaly T, Greene P, Breeze R, Fahn S, Freed C, Dhawan V, Eidelberg D: Dopamine cell implantation in Parkinson's disease: long-term clinical and (18)F-FDOPA PET outcomes. J Nucl Med 2010, 51:7-15.

14. Freed CR, Greene PE, Breeze RE, Tsai WY, DuMouchel W, Kao R, Dillon S, Winfield H, Culver S, Trojanowski JQ, Eidelberg D, Fahn S: Transplantation of embryonic dopamine neurons for severe Parkinson's disease. N Engl J Med 2001, 344:710-719.

15. Isacson O, Kordower JH: Future of cell and gene therapies for Parkinson's disease. Ann Neurol 2008, 64 Suppl 2:S122-138.
16. Politis M, Wu K, Loane C, Quinn NP, Brooks DJ, Rehncrona S, Bjorklund A, Lindvall O, Piccini P: Serotonergic neurons mediate dyskinesia side effects in Parkinson's patients with neural transplants. Sci Transl Med 2010, 2:38ra46.

17. Braak H, Del Tredici $K$ : Assessing fetal nerve cell grafts in Parkinson's disease. Nat Med 2008, 14:483-485.

18. Thomson JA, Itskovitz-Eldor J, Shapiro SS, Waknitz MA, Swiergiel JJ, Marshall VS, Jones JM: Embryonic stem cell lines derived from human blastocysts. Science 1998, 282:1145-1147.

19. Hargus G, Cooper O, Deleidi M, Levy A, Lee K, Marlow E, Yow A, Soldner F, Hockemeyer D, Hallett PJ, Osborn T, Jaenisch R, Isacson O: Differentiated Parkinson patient-derived induced pluripotent stem cells grow in the adult rodent brain and reduce motor asymmetry in Parkinsonian rats. Proc Natl Acad Sci U S A 2010, 107:15921-15926.

20. Soldner F, Hockemeyer D, Beard C, Gao Q, Bell GW, Cook EG, Hargus G, Blak A, Cooper O, Mitalipova M, Isacson O, Jaenisch R: Parkinson's disease patientderived induced pluripotent stem cells free of viral reprogramming factors. Cell 2009, 136:964-977.

21. Perrier AL, Tabar V, Barberi T, Rubio ME, Bruses J, Topf N, Harrison NL, Studer L: Derivation of midbrain dopamine neurons from human embryonic stem cells. Proc Natl Acad Sci U S A 2004, 101:12543-12548.

22. Zeng X, Cai J, Chen J, Luo Y, You ZB, Fotter E, Wang Y, Harvey B, Miura T, Backman C, Chen GJ, Rao MS, Freed WJ: Dopaminergic differentiation of human embryonic stem cells. Stem Cells 2004, 22:925-940.

23. Ben-Hur T, Idelson M, Khaner H, Pera M, Reinhartz E, Itzik A, Reubinoff BE: Transplantation of human embryonic stem cell-derived neural progenitors improves behavioral deficit in Parkinsonian rats. Stem Cells 2004, 22:1246-1255.

24. Yang D, Zhang ZJ, Oldenburg M, Ayala M, Zhang SC: Human embryonic stem cell-derived dopaminergic neurons reverse functional deficit in parkinsonian rats. Stem Cells 2008, 26:55-63.

25. Chiba S, Lee YM, Zhou W, Freed CR: Noggin enhances dopamine neuron production from human embryonic stem cells and improves behavioral outcome after transplantation into Parkinsonian rats. Stem Cells 2008, 26:2810-2820

26. Swistowski A, Peng J, Han Y, Swistowska AM, Rao MS, Zeng X: Xeno-free defined conditions for culture of human embryonic stem cells, neural stem cells and dopaminergic neurons derived from them. PLoS One 2009, 4:e6233.

27. Roy NS, Cleren C, Singh SK, Yang L, Beal MF, Goldman SA: Functiona engraftment of human ES cell-derived dopaminergic neurons enriched by coculture with telomerase-immortalized midbrain astrocytes. Nat Med 2006, 12:1259-1268.

28. Park CH, Minn YK, Lee JY, Choi DH, Chang MY, Shim JW, Ko JY, Koh HC, Kang MJ, Kang JS, Rhie DJ, Lee YS, Son H, Moon SY, Kim KS, Lee SH: In vitro and in vivo analyses of human embryonic stem cell-derived dopamine neurons. J Neurochem 2005, 92:1265-1276.

29. Park S, Lee KS, Lee YJ, Shin HA, Cho HY, Wang KC, Kim YS, Lee HT, Chung KS, Kim EY, Lim J: Generation of dopaminergic neurons in vitro from human embryonic stem cells treated with neurotrophic factors. Neurosci Lett 2004 359:99-103.

30. Buytaert-Hoefen KA, Alvarez E, Freed CR: Generation of tyrosine hydroxylase positive neurons from human embryonic stem cells after coculture with cellular substrates and exposure to GDNF. Stem Cells 2004, 22:669-674.

31. Schulz TC, Noggle SA, Palmarini GM, Weiler DA, Lyons IG, Pensa KA, Meedeniya AC, Davidson BP, Lambert NA, Condie BG: Differentiation of human embryonic stem cells to dopaminergic neurons in serum-free suspension culture. Stem Cells 2004, 22:1218-1238.

32. Yan Y, Yang D, Zarnowska ED, Du Z, Werbel B, Valliere C, Pearce RA, Thomson JA, Zhang SC: Directed differentiation of dopaminergic neuronal subtypes from human embryonic stem cells. Stem Cells 2005, 23:781-790.

33. Swistowska AM, da Cruz AB, Han Y, Swistowski A, Liu Y, Shin S, Zhan M, Rao MS, Zeng X: Stage-specific role for shh in dopaminergic differentiation of human embryonic stem cells induced by stromal cells. Stem Cells Dev 2010, 19:71-82.

34. Lee SH, Lumelsky N, Studer L, Auerbach JM, McKay RD: Efficient generation of midbrain and hindbrain neurons from mouse embryonic stem cells. Nat Biotechnol 2000, 18:675-679.

35. Reubinoff BE, Itsykson P, Turetsky T, Pera MF, Reinhartz E, Itzik A, Ben-Hur T: Neural progenitors from human embryonic stem cells. Nat Biotechnol 2001, 19:1134-1140. 
36. Zhang SC, Wernig M, Duncan ID, Brüstle O, Thomson JA: In vitro differentiation of transplantable neural precursors from human embryonic stem cells. Nat Biotechnol 2001, 19:1129-1133.

37. Kawasaki H, Mizuseki K, Nishikawa S, Kaneko S, Kuwana Y, Nakanishi S, Nishikawa SI, Sasai Y: Induction of midbrain dopaminergic neurons from ES cells by stromal cell-derived inducing activity. Neuron 2000, 28:31-40.

38. Takagi Y, Takahashi J, Saiki H, Morizane A, Hayashi T, Kishi Y, Fukuda H, Okamoto Y, Koyanagi M, Ideguchi M, Hayashi H, Imazato T, Kawasaki H, Suemori H, Omachi S, lida H, Itoh N, Nakatsuji N, Sasai Y, Hashimoto N: Dopaminergic neurons generated from monkey embryonic stem cells function in a Parkinson primate model. J Clin Invest 2005, 115:102-109.

39. Vazin T, Becker KG, Chen J, Spivak CE, Lupica CR, Zhang Y, Worden L, Freed WJ: A novel combination of factors, termed SPIE, which promotes dopaminergic neuron differentiation from human embryonic stem cells. PLoS One 2009, 4:e6606.

40. Fasano CA, Chambers SM, Lee G, Tomishima MJ, Studer L: Efficient derivation of functional floor plate tissue from human embryonic stem cells. Cell Stem Cell 2010, 6:336-347.

41. Cooper O, Hargus G, Deleidi M, Blak A, Osborn T, Marlow E, Lee K, Levy A, Perez-Torres E, Yow A, Isacson O: Differentiation of human ES and Parkinson's disease iPS cells into ventral midbrain dopaminergic neurons requires a high activity form of $\mathrm{SHH}$, FGF8a and specific regionalization by retinoic acid. Mol Cell Neurosci 2010, 45:258-266.

42. Cai J, Yang M, Poremsky E, Kidd S, Schneider JS, lacovitti L: Dopaminergic neurons derived from human induced pluripotent stem cells survive and integrate into 6-OHDA-lesioned rats. Stem Cells Dev 2010, 19:1017-1023.

43. Wernig M, Zhao JP, Pruszak J, Hedlund E, Fu D, Soldner F, Broccoli V, Constantine-Paton M, Isacson $\mathrm{O}$, Jaenisch R: Neurons derived from reprogrammed fibroblasts functionally integrate into the fetal brain and improve symptoms of rats with Parkinson's disease. Proc Natl Acad Sci U S A 2008, 105:5856-5861.

44. Erdö F, Bührle C, Blunk J, Hoehn M, Xia Y, Fleischmann B, Föcking M, Küstermann E, Kolossov E, Hescheler J, Hossmann KA, Trapp T: Hostdependent tumorigenesis of embryonic stem cell transplantation in experimental stroke. J Cereb Blood Flow Metab 2003, 23:780-785.

45. Hedlund E, Pruszak J, Ferree A, Viñuela A, Hong S, Isacson O, Kim KS: Selection of embryonic stem cell-derived enhanced green fluorescent proteinpositive dopamine neurons using the tyrosine hydroxylase promoter is confounded by reporter gene expression in immature cell populations. Stem Cells 2007, 25:1126-1135.
46. Schein JC, Hunter DD, Roffler-Tarlov S: Girk2 expression in the ventral midbrain, cerebellum, and olfactory bulb and its relationship to the murine mutation weaver. Dev Biol 1998, 204:432-450.

47. Lister R, Pelizzola M, Kida YS, Hawkins RD, Nery JR, Hon G, AntosiewiczBourget J, O'Malley R, Castanon R, Klugman S, Downes M, Yu R, Stewart R, Ren B, Thomson JA, Evans RM, Ecker JR: Hotspots of aberrant epigenomic reprogramming in human induced pluripotent stem cells. Nature 2011, 471:68-73

48. Bar-Nur O, Russ HA, Efrat S, Benvenisty N: Epigenetic memory and preferential lineage-specific differentiation in induced pluripotent stem cells derived from human pancreatic islet Beta cells. Cell Stem Cell 2011, 9:17-23.

49. Swistowski A, Peng J, Liu Q, Mali P, Rao MS, Cheng L, Zeng X: Efficient generation of functional dopaminergic neurons from human induced pluripotent stem cells under defined conditions. Stem Cells 2010, 28:1893-1904.

50. Ma L, Liu Y, Zhang SC: Directed differentiation of dopamine neurons from human pluripotent stem cells. Methods Mol Biol 2011, 767:411-418.

51. Mayshar Y, Ben-David U, Lavon N, Biancotti JC, Yakir B, Clark AT, Plath K, Lowry WE, Benvenisty N: Identification and classification of chromosomal aberrations in human induced pluripotent stem cells. Cell Stem Cell 2010 7:521-531.

52. Hussein SM, Batada NN, Vuoristo S, Ching RW, Autio R, Närvä E, Ng S, Sourour M, Hämäläinen R, Olsson C, Lundin K, Mikkola M, Trokovic R, Peitz M, Brüstle O, Bazett-Jones DP, Alitalo K, Lahesmaa R, Nagy A, Otonkoski T: Copy number variation and selection during reprogramming to pluripotency. Nature 2011, 471:58-62

53. Koehler KR, Tropel P, Theile JW, Kondo T, Cummins TR, Viville S, Hashino E: Extended passaging increases the efficiency of neural differentiation from induced pluripotent stem cells. BMC Neurosci 2011, 12:82

doi:10.1186/scrt173

Cite this article as: Zeng $X$, Couture LA: Pluripotent stem cells for Parkinson's disease: progress and challenges. Stem Cell Research \& Therapy 2013, 4:25. 